\title{
EFEK KOMPOSISI BEBERAPA MEDIA TANAM TERHADAP PERTUMBUHAN DAN PRODUKSI TANAMAN CABAI RAWIT (Capsicum frutescens $\mathrm{L}$. )
}

\author{
Yusmaidar Sepriani, Yudi Triyanto, Primadani \\ Program Studi Agroteknologi, Fakultas Sains dan Teknologi, Universitas Labuhan Batu \\ Jln. SM. Raja No. 126 A Aek Tapa Rantauprapat \\ Email : triyantoyudi81@gmail.com
}

\begin{abstract}
ABSTRACK
This study aims to determine the composition effect of several growing media on the growth and production of cayenne pepper (Capsicum frutescens L). This research was carried out on the Labuhanbatu STIPER trial field, Jln. Manunggal AMD, Bakaran Batu Village, Rantau Selatan District, Labuhanbatu Regency, North Sumatra Province which began from December 2018 to March 2019. The experimental design used was Non Factorial Randomized Block Design (RBD) and each treatment was repeated 3 (three) times. Treatment consists of: $P 0=$ Land (control), $P 1$ = Solid + Land (1:3), P2 = Cow Manure + Soil (1:3), P3 = Sand + Soil (1: 3), P4 = Land + Solid + Cow Manure (2: 1: 1), P5 = Land + Solid + Sand (2: 1: 1), P6 = Soil + Cow Manure + Sand (2: 1: 1), P7 = Land + Solid + Cow + Sand Manure (1: 1: 1: 1). The results showed that the composition of solid + soil planting media with a ratio of $1: 3(P 1)$ can increase plant height, number of leaves and stem diameter of cayenne pepper plants. In the composition of soil + solid planting media + cow manure with a ratio of $2: 1: 1(P 4)$ can increase the weight of fruit crops and the number of fruit crops in cayenne pepper plants.
\end{abstract}

Keywords: composition of planting media, cayenne pepper (Capsicum frutescens L).

\section{PENDAHULUAN}

\subsection{Latar Belakang}

Cabai rawit (Capsicum frutescens L.)

merupakan salah satu tanaman hortikultura dari jenis sayuran yang memiliki buah kecil dengan rasa yang pedas. Cabai jenis ini dibudidayakan oleh para petani karena banyak dibutuhkan masyarakat, tidak hanya dalam skala rumah tangga, tetapi juga digunakan dalam skala industri, dan dieksport ke luar negeri (Ashari, 1995).
Penanaman cabai membutuhkan lahan yang luas akan tetapi sejalan dengan laju pertumbuhan penduduk yang semakin meningkat, proses perubahan bentuk penggunaan lahan ini akan berlangsung terus-menerus secara berkesinambungan menjadikan lahan semakin sempit (Wahyudi, 2009).

Media tanam merupakan salah satu unsur penting yang menunjang pertumbuhan 
tanaman. Sebagian besar unsur - unsur hara yang dibutuhkan tanaman disediakan melalui media tanam, selanjutnya diserap oleh perakaran dan digunakan untuk proses fisiologis tanaman (Ermina, 2010).

Media tanam yang umum digunakan adalah tanah, karena di dalam tanah tersedia faktor - faktor utama untuk pertumbuhan tanaman seperti unsur hara, air, dan udara (Ningrum, 2010).

Komposisi dalam media tanam perlu diperhatikan. komposisi campuran media tanam antara pasir dan tanah yaitu dengan perbandingan 1 : 1 . Perbandingan tersebut dapat dikatakan memiliki komposisi yang sama besar antara ketersediaan tanah dengan pasir (Haryoto, 2009).

Berdasarkan penelitian (Mulyati, 2009), pengaruh kandungan campuran pasir terhadap persemaian tanaman cabai rawit terhadap penyakit rebah kecambah (Sclerotium rolfsii Sacc), bahwa pada komposisi antara pasir dan tanah yang memiliki perbandingan 1:1 menunjukkan pengaruh yang baik terhadap infeksi patogen rebah kecambah.

Hasil penelitian menunjukkan bahwa perlakuan media tanam berpengaruh nyata terhadap umur berbunga, jumlah buah/sampel dan bobot buah/sampel, tetapi berpengaruh tidak nyata terhadap tinggi tanaman, diameter batang dan jumlah cabang/sampel (Silvianti, 2012).

Di areal sempit dan terbatas, seperti di pekarangan sekitar rumah, budidaya cabai dapat dilakukan dengan menggunakan polybag. Polybag sangat praktis untuk budidaya tanaman cabai pada areal terbatas. Budidaya tanaman cabai dengan polybag dapat menghasilkan panen yang cukup memuaskan jika dilakukan dengan teknik budidaya yang baik. Semua jenis tanaman cabai dapat dibudidayakan dengan menggunakan polybag (Salim, 2013).

Selama ini, cabai banyak di tanam di lahan seperti sawah dan ladang. Padahal, tanaman ini juga dapat dibudidayakan dengan menggunakan media penanaman yang terbatas. Contoh yang paling kongkret adalah budidaya cabai rawit di dalam wadah seperti polybag, atau pot. Dengan cara seperti ini ada dua manfaat yang sekaligus dapat dipetik, yakni dapat mengoptimalkan pekarangan sempit dan dapat memanfaatkan barang-barang bekas sebagai wadah penanaman. Dengan begitu, keterbatasan lahan bukanlah kendala untuk tetap menjadikannya produktif (Purwono, 2003).

\subsection{Tujuan Penelitian}

Mengetahui efek komposisi beberapa media tanam terhadap pertumbuhan dan 
produksi tanaman cabai rawit (Capsicum frutescens $\mathrm{L}$ ).

\section{METODE PENELITIAN}

Penelitian dilakukan dengan menggunakan Rancangan Acak Kelompok (RAK) Non Faktorial dengan perlakuan media tanam sebagai berikut:

P0: Tanah (Kontrol)

P1: Solid + Tanah (1:3)

P2: Pupuk Kandang Sapi + Tanah (1:3)

P3: Pasir + Tanah (1:3)

P4: Tanah + Solid + Pupuk Kandang Sapi $(2: 1: 1)$

P5: Tanah + Solid + Pasir $(2: 1: 1)$

P6: Tanah + Pupuk Kandang Sapi + Pasir $(2: 1: 1)$

P7: Tanah + Solid + Pupuk Kandang Sapi + Pasir $(1: 1: 1: 1)$

$\begin{array}{ll}\text { Jumlah Ulangan } & : 3 \\ \text { Jumlah Percobaan } & : 8 \\ \text { Jumlah polybag } & : 48 \\ \text { Jumlah tanaman / polybag } & : 1 \\ \text { Jumlah tanaman seluruhnya } & : 48 \\ \text { Jumlah sampel / polybag } & : 1 \text { tanaman } \\ \text { Jumlah seluruh sampel } & : 24 \text { tanaman }\end{array}$

Dari hasil penelitian dianalisis dengan menggunakan sidik ragam berdasarkan model linier sebagai berikut :

$$
\begin{gathered}
Y_{i j}=\mu+\rho_{i}+\alpha_{j}+\varepsilon_{i j} \\
i=1,2,3 j=0,1,2,3,4,5,6,7
\end{gathered}
$$

Yij $\quad=$ Hasil pengamatan untuk unit percobaan ke-i dan perlakuan media tanam taraf ke-j

$\mu \quad=$ Nilai tengah umum

$\rho_{\mathrm{i}} \quad=$ Efek dari blok ke-i

$\alpha_{\mathrm{j}} \quad=$ Efek perlakuan median tanam taraf ke-j

eij = Galat dari blok ke-i dan perlakuan media tanam taraf ke-j

\section{HASIL DAN PEMBAHASAN}

Dari hasil penelitian tentang efek komposisi beberapa media tanam terhadap pertumbuhan dan produksi tanaman cabai rawit (Capsicum frutescens L.) diperoleh hasil penelitian dari beberapa pengamatan parameter sebagai berikut :

\subsection{Tinggi Tanaman (cm)}

Hasil analisis sidik ragam tentang efek komposisi media tanam terhadap pertumbuhan dan produksi tanaman cabai rawit pada tinggi tanaman cabai rawit umur 8 minggu setelah tanam (MST) (Tabel 1). 
Tabel 1. Hasil uji Duncan 5\% tinggi tanaman cabai rawit umur 8 MST pada berbagai perlakuan komposisi media tanam.

\begin{tabular}{lcc}
\hline \multicolumn{1}{c}{ Perlakuan Media Tanam } & $\begin{array}{c}\text { Rataan Tinggi } \\
\text { Tanaman }\end{array}$ & Notasi \\
\hline P0 : Tanah (Kontrol) & 30,83 & A \\
P1 : Solid + Tanah (1:3) & 63,67 & E \\
P2 : Pupuk Kandang Sapi + Tanah (1:3) & 53,17 & Cd \\
P3 : Pasir + Tanah (1:3) & 26,83 & A \\
P4 : Tanah + Solid + Pupuk Kandang Sapi $(2: 1: 1)$ & 60,00 & De \\
P5 : Tanah + Solid + Pasir (2:1:1) & 44,50 & B \\
P6 : Tanah + Pupuk Kandang Sapi + Pasir (2:1:1) & 49,00 & bc \\
P7 : Tanah + Solid + Pupuk Kandang Sapi + Pasir $(1: 1: 1: 1)$ & 55,17 & cd \\
\hline
\end{tabular}

Keterangan : Nilai rata-rata pada kolom yang sama yang diikuti huruf yang sama menunjukan tidak berbeda nyata pada uji DMRT taraf $5 \%$.

Pada tabel hasil Duncan didapatkan bahwa hasil tertinggi terdapat pada perlakuan P1 yang berbeda nyata dengan perlakuan P0, P2, P3, P5, P6 dan P7. Hasil terendah terdapat pada perlakuan P3.

\subsection{Jumlah Daun (helai)}

Hasil analisis sidik ragam tentang efek komposisi media tanam terhadap pertumbuhan dan produksi tanaman cabai rawit pada jumlah daun tanaman cabai rawit umur 8 minggu setelah tanam (MST) (Tabel 2).

Tabel 2. Analisis sidik ragam jumlah daun tanaman cabai rawit umur 8 MST pada berbagai perlakuan komposisi media tanam.

\begin{tabular}{lcc}
\hline \multicolumn{1}{c}{ Perlakuan Media Tanam } & Rataan Jumlah & Notasi \\
& Daun & \\
\hline P0 : Tanah (Kontrol) & 32,00 & $\mathrm{a}$ \\
P1 : Solid + Tanah (1:3) & 129,33 & $\mathrm{~d}$ \\
P2 : Pupuk Kandang Sapi + Tanah (1:3) & 99,67 & $\mathrm{~b}$ \\
P3 : Pasir + Tanah (1:3) & 28,67 & $\mathrm{a}$ \\
P4 : Tanah + Solid + Pupuk Kandang Sapi $(2: 1: 1)$ & 120,33 & $\mathrm{~cd}$ \\
P5 : Tanah + Solid + Pasir (2:1:1) & 110,33 & $\mathrm{bc}$ \\
P6 : Tanah + Pupuk Kandang Sapi + Pasir (2:1:1) & 124,33 & $\mathrm{~d}$ \\
P7 : Tanah + Solid + Pupuk Kandang Sapi + Pasir $(1: 1: 1: 1)$ & 121,67 & $\mathrm{~cd}$ \\
\hline \hline
\end{tabular}


Keterangan : Nilai rata-rata pada kolom yang sama yang diikuti huruf yang sama menunjukan tidak berbeda nyata pada uji DMRT taraf $5 \%$.

Pada tabel hasil Duncan didapatkan

bahwa hasil tertinggi terdapat pada

perlakuan P1 yang berbeda nyata dengan

perlakuan P0, P2, P3 dan P5. Hasil terendah

terdapat pada perlakuan $\mathrm{P}$.

\subsection{Diameter Batang ( $\mathrm{mm})$}

Hasil analisis sidik ragam tentang efek komposisi media tanam terhadap pertumbuhan dan produksi tanaman cabai rawit pada diameter batang tanaman cabai rawit umur 8 minggu setelah tanam (MST) (Tabel 3).

Tabel 3. Analisis sidik ragam diameter batang tanaman cabai rawit umur 8 MST pada berbagai perlakuan komposisi media tanam.

\begin{tabular}{lcc}
\hline \multicolumn{1}{c}{ Perlakuan Media Tanam } & $\begin{array}{c}\text { Rataan Diameter } \\
\text { Batang }\end{array}$ & Notasi \\
\hline P0 : Tanah (Kontrol) & 7,82 & $\mathrm{~b}$ \\
P1 : Solid + Tanah (1:3) & 16,00 & $\mathrm{e}$ \\
P2 : Pupuk Kandang Sapi + Tanah (1:3) & 12,50 & $\mathrm{~d}$ \\
P3 : Pasir + Tanah (1:3) & 5,23 & $\mathrm{a}$ \\
P4 : Tanah + Solid + Pupuk Kandang Sapi $(2: 1: 1)$ & 12,13 & $\mathrm{~d}$ \\
P5 : Tanah + Solid + Pasir (2:1:1) & 6,95 & $\mathrm{~b}$ \\
P6 : Tanah + Pupuk Kandang Sapi + Pasir (2:1:1) & 10,68 & $\mathrm{c}$ \\
P7 : Tanah + Solid + Pupuk Kandang Sapi + Pasir $(1: 1: 1: 1)$ & 12,58 & $\mathrm{~d}$ \\
\hline
\end{tabular}

Keterangan : Nilai rata-rata pada kolom yang sama yang diikuti huruf yang sama menunjukan tidak berbeda nyata pada uji DMRT taraf 5 \%.Pada tabel hasil Duncan didapatkan bahwa hasil tertinggi terdapat pada perlakuan P1 yang berbeda nyata dengan perlakuan lainnya.

\subsection{Berat Buah Pertanaman (g)}

Hasil analisis sidik ragam tentang efek komposisi media tanam terhadap pertumbuhan dan produksi tanaman cabai rawit pada berat buah pertanaman cabai rawit (Tabel 4).

Tabel 4. Analisis sidik ragam berat buah pertanaman cabai rawit pada berbagai perlakuan komposisi media tanam.

Perlakuan Media Tanam

Rataan Berat Buah Pertanaman
Notasi

$\begin{array}{cc}4,33 & \mathrm{a} \\ 62,00 & \mathrm{de}\end{array}$


P2 : Pupuk Kandang Sapi + Tanah $(1: 3)$

$\begin{array}{cc}36,00 & \mathrm{bc} \\ 3,67 & \mathrm{a} \\ 73,33 & \mathrm{e} \\ 55,00 & \mathrm{~cd} \\ 27,67 & \mathrm{ab} \\ 43,67 & \mathrm{bc}\end{array}$

P3 : Pasir + Tanah $(1: 3)$

P4 : Tanah + Solid + Pupuk Kandang Sapi $(2: 1: 1)$

P5 : Tanah + Solid + Pasir $(2: 1: 1)$

d

P6 : Tanah + Pupuk Kandang Sapi + Pasir (2:1:1)

$\mathrm{ab}$

P7 : Tanah + Solid + Pupuk Kandang Sapi + Pasir (1:1:1:1)

bc

Keterangan : Nilai rata-rata pada kolom yang sama yang diikuti huruf yang sama menunjukan tidak berbeda nyata pada uji DMRT taraf $5 \%$.

Pada tabel hasil Duncan didapatkan bahwa hasil tertinggi terdapat pada perlakuan P4 yang berbeda nyata dengan perlakuan P0, P2, P3, P5, P6 dan P7. Hasil terendah terdapat pada perlakuan $\mathrm{P} 3$.

\subsection{Jumlah Buah Pertanaman (buah)}

Hasil analisis sidik ragam tentang efek komposisi media tanam terhadap pertumbuhan dan produksi tanaman cabai rawit pada jumlah buah pertanaman cabai rawit (Tabel 5).

Tabel 5. Analisis sidik ragam jumlah buah pertanaman cabai rawit pada berbagai perlakuan komposisi media tanam.

\begin{tabular}{lcc}
\hline \multicolumn{1}{c}{ Perlakuan Media Tanam } & $\begin{array}{c}\text { Rataan Jumlah } \\
\text { Buah Pertanaman }\end{array}$ & Notasi \\
\hline P0 : Tanah (Kontrol) & 6,00 & $\mathrm{a}$ \\
P1 : Solid + Tanah (1:3) & 116,33 & $\mathrm{de}$ \\
P2 : Pupuk Kandang Sapi + Tanah (1:3) & 64,67 & $\mathrm{bc}$ \\
P3 : Pasir + Tanah (1:3) & 4,33 & $\mathrm{a}$ \\
P4 : Tanah + Solid + Pupuk Kandang Sapi (2:1:1) & 133,67 & $\mathrm{e}$ \\
P5 : Tanah + Solid + Pasir (2:1:1) & 103,67 & $\mathrm{~cd}$ \\
P6 : Tanah + Pupuk Kandang Sapi + Pasir (2:1:1) & 42,67 & $\mathrm{ab}$ \\
P7 : Tanah + Solid + Pupuk Kandang Sapi + Pasir (1:1:1:1) & 78,67 & $\mathrm{bc}$ \\
\hline
\end{tabular}

Keterangan : Nilai rata-rata pada kolom yang sama yang diikuti huruf yang sama menunjukan tidak berbeda nyata pada uji DMRT taraf $5 \%$.

Pada tabel hasil Duncan didapatkan bahwa hasil tertinggi terdapat pada perlakuan P4 yang berbeda nyata dengan perlakuan P0, P2, P3, P5, P6 dan P7. Hasil terendah terdapat pada perlakuan P3.

Berdasarkan hasil analisis sidik ragam dapat diketahui bahwa efek 
komposisi beberapa media tanam berpengaruh nyata terhadap parameter tinggi tanaman, jumlah daun, diameter batang, berat buah pertanaman dan jumlah buah pertanaman pada setiap perlakuan. Pada perlakuan P1 (Solid + Tanah 1 : 3) menghasilkan nilai tertinggi terhadap parameter tinggi tanaman, jumlah daun, diameter batang di umur 8 MST.

Adanya pengaruh nyata pada tinggi tanaman, jumlah daun, diameter batang di umur 8 MST disebabkan komposisi media tanam pada perlakuan P1 (Solid + Tanah 1:3) tepat karena solid mampu memperbaiki sifat fisik, kimia, dan biologi tanah.

\section{KESIMPULAN DAN SARAN}

\section{Kesimpulan}

1. Komposisi media tanam berpengaruh nyata terhadap tinggi tanaman, jumlah daun, diameter batang, berat buah pertanaman dan jumlah buah pertanaman.

2. Komposisi media tanam yang terbaik adalah pada perlakuan P1 (solid + tanah dengan perbandingan $1: 3$ ) dan perlakuan P4 $(\operatorname{tanah}+$ solid + pupuk kandang dengan perbandingan $2: 1: 1)$ dapat memberikan pertumbuhan dan produksi yang tinggi bagi tanaman cabai rawit.

\section{Saran}

1. Perlakuan komposisi media tanam yang disarankan untuk tanaman cabai rawit adalah tanah + solid + pupuk kandang dengan perbandingan 2: 1:1

2. Perlu dilakukan penelitian lanjutan mengenai perlakuan tersebut guna mengetahui pengaruhnya terhadap pertumbuhan dan produksi tanaman jenis lain.

\section{DAFTAR PUSTAKA}

Ashari, 1995. Hortikultura Aspek Budidaya. Buku Penerbt Universitas Indonesia. Jakarta. 141-146p.

Ermina, Y., 2010, Media Tanaman Hidroponik dari Arang Sekam, Balai Besar Pelatihan Pertanian (BBPP Lembang).

Haryoto, 2009, Bertanam Cabai Rawit dalam Pot, Kanisius: Yogyakarta.

Mulyati, S., 2009, Pengaruh Kandungan Pasir Pada Media Semai Terhadap Penyakit Rebah Kecambah (Sclerotium rolfsii Sacc) Pada Persemaian Tanaman Cabai, Jurnal Agronomi, 13 (1), 45 - 50.

Ningrum, F. G. K., 2010, Efektivitas Air Kelapa dan Ampas Teh Terhadap Pertumbuhan Tanaman Mahkota Dewa (Phaleria macrocarpa) Pada 
Media Tanam Yang Berbeda, Skripsi Program Studi Pendidikan Biologi Fakultas Keguruan dan Ilmu Pendidikan Universitas Muhammadiyah Surakarta.

Purwono, 2003. Bertanam Cabai Rawit Dalam Pot. Tim Lentera, Jakarta.

Salim, E. 2013. Meraup Untung Bertanam Cabe Hibrida Unggul Dilahan dan Polybag. Yogyakarta.

Silvianti, D. 2012. Pengaruh Media Tanam Dan Pupuk Organik NPK Terhadap Pertumbuhan Dan Produksi Cabai Rawit (Capsicum frutescens L.). Fakultas Pertanian Universitas Sumatera Utara. Medan.

Wahyudi, E. B., 2009, Analisis Perubahan Penggunaan Lahan di Kecamatan Sokaraja Kabupaten Banyumas Tahun 1994 dan 2004, Skripsi Fakultas Geografi Universitas Muhammadiyah Surakarta. 